RUNNING HEAD: A BLAST FROM THE PAST

\title{
A Blast from the Past: The Terror Management Function of Nostalgia
}

\author{
Clay Routledge \\ University of Southampton \\ Jamie Arndt \\ University of Missouri-Columbia \\ Constantine Sedikides \\ University of Southampton \\ Tim Wildschut \\ University of Southampton
}

Correspondence concerning this article should be addressed to:

Clay Routledge

Center for Research on Self and Identity

School of Psychology

University of Southampton

Southampton, SO17 1BJ

England, UK

Phone 44 (0) 2380594584

Email: C.D.Routledge@soton.ac.uk 


\begin{abstract}
According to terror management theory, people turn to meaning-providing structures to cope with the knowledge of inevitable mortality. Recent theory and research suggest that nostalgia serves such an existential function by supplying a reservoir of meaningful life experiences which can be used as a defense against death concerns. The current research tests and supports this idea. In Experiments 1 and 2, nostalgia proneness was measured and mortality salience manipulated. In Experiment 1, when mortality was salient, the more prone to nostalgia participants were, the more they perceived life to be meaningful. In Experiment 2, when mortality was salient, the more prone to nostalgia participants were, the less death thoughts were accessible. In Experiment 3, nostalgia and mortality salience were manipulated. It was found that nostalgia buffered the effects of mortality salience on death-thought accessibility.
\end{abstract}

\title{
$\underline{\text { Keywords }}$
}

Nostalgia

Mortality Salience

Death-Thought Accessibility

Meaninglessness

Self-protection 


\section{A Blast from the Past: The Terror Management Function of Nostalgia}

The ability to think in terms of time, combined with other cognitive capacities, renders humans cognizant of the inescapable reality of their mortality (Becker, 1971; Routledge \& Arndt, 2005). Interestingly, the same capacities that reveal people's transience may also facilitate their transcendence. Though temporal consciousness may be complicit in creating an awareness of death, this ability may also be deployed to protect oneself from the potential consequences of death-related cognition. Research derived from terror management theory (TMT: Greenberg, Pyszczynski, \& Solomon, 1986) has focused on a wide range of behaviors that reflect efforts to reinforce a sense of meaning in the face of the awareness of mortality (e.g., defense of cultural worldviews, self-esteem strivings, efforts to deny similarities to other animals, efforts to perceive the world as coherent and just; Greenberg, Solomon, \& Arndt, in press), but has yet to explore the potential for people to reflect on past life experiences to affirm a sense of meaning in the present.

Recent theory and research examining the psychological landscape of nostalgia suggests that this experience might be an especially potent means of terror management. Sedikides, Wildschut, and Baden (2004) proposed that nostalgic reverie provides a reservoir of meaningful life experiences to draw upon when facing existential threat. Accordingly, research indicates nostalgic reverie often revolves around momentous life events (Wildschut, Sedikides, Arndt, \& Routledge, 2006). However, while there are some suggestive findings, no research has yet examined the potential for nostalgia to provide a defense against an existential threat. The current investigation explores the extent to which nostalgia provides protection from threatening cognitions about death. 
TMT (Greenberg et al., 1986) focuses on how humans cope with the awareness of mortality and suggests that people buffer the potential for death-related anxiety by advocating cultural worldviews that imbue their life with meaning, by striving to attain and maintain feelings of self-worth, and by investing in personal relationships. Experiments have supported these theoretical postulates by demonstrating that (a) the activation of death thoughts (mortality salience; MS) increases defense of one's worldview, strivings to maintain self-esteem, as well as investment in close relationships, and (b) bolstering each of these structures either before or after MS attenuates further the need to deploy psychological defenses (Mikulincer, Florian, \& Hirschberger, 2003; Pyszczynski et al., 2004). Despite the wide scope of the TMT literature, research has yet to consider whether the ability to reflect emotionally on the past facilitates efforts to defend against threats to the self, and in particular, the threat of death-awareness. This is a critical gap not just with regard to terror management, but in the social psychological literature more broadly (Sedikides, Wildschut, Arndt, \& Routledge, 2006), given the pervasiveness of nostalgia (i.e., $80 \%$ of survey respondents report feeling nostalgic at least once a week; Wildschut et al., 2006).

The New Oxford Dictionary of English (1998) defines "nostalgia" as "a sentimental longing for the past." Drawing from this definition, a revitalization of interest in the construct has focused on its positive and self-relevant implications (Sedikides et al., 2004, 2006). From this perspective, nostalgia is a self-relevant emotional reflection on the past that serves four specific psychological functions. First, it serves as a repository of positive feelings. Wildschut et al. (2006) found that nostalgic accounts, as rated by coders, reflected more positive than negative emotions, contained more desirable than undesirable features, and led to more positive than negative mood. Thus, although nostalgia can at times be bittersweet, it is principally a positive 
emotional experience. Second, nostalgia contributes to self-positivity. Wildschut et al. found that participants who brought to mind and wrote about a nostalgic experience reported higher selfesteem than control group participants. Third, nostalgia strengthens social connectedness. In Wildschut et al., participants who wrote about a nostalgic experience subsequently demonstrated a more secure adult attachment style than control group participants, as well as greater confidence with initiating interpersonal relationships.

Though these first three hypothesized functions have recently been empirically explored, a fourth function has also been proposed, but has not received direct empirical attention. Specifically, it has been asserted that nostalgia may provide perceptions of meaning in life that facilitate coping with existential concerns (Routledge \& Arndt, 2005; Sedikides et al., 2004). Broadly consistent with this position, Wildschut and colleagues (2006) found the subject of nostalgia was often momentous and thus highly meaningful life events. However, while there are some suggestive findings, no research has directly examined the potential for nostalgia to serve an existential function. The present research explores this potential.

\section{Experiment 1}

We initially examined the possibility that nostalgia serves an existential function by testing whether nostalgic tendencies are related to perceptions of meaning in response to reminders of death. According to TMT, people seek meaning in life, in part, to manage insecurities related to mortality awareness. Indeed, as mentioned previously, MS increases investment in meaning-providing structures. Such reactions include not only the aforementioned investments in cultural beliefs and values, but also a preference for basic structure and meaningful representations (e.g., structured vs. abstract art; Landau et al., 2004). Presumably, then, reminders of mortality would undermine perceptions of meaning, thus motivating efforts to 
derive or restore meaning. If nostalgia serves a meaning-providing function, in the context of terror-management processes wherein meaning-relevant defenses are needed following reminders of mortality, higher levels of nostalgia should be associated with greater perceptions of meaning. To test this proposition, we measured the propensity to think positively about the past - as a proxy for nostalgia proneness - then induced MS, and assessed perceptions of meaning in life.

\section{Method $^{1}$}

Seventy-six individuals (54 female, 22 male) completed a packet of materials beginning with filler personality measures to bolster the cover story, and followed by 8 items from the Time Perspective Inventory (TPI; Zimbardo \& Boyd, 1999). The complete TPI consists of 56 items measuring attitudes toward the past, present, and future. Here we were only interested in attitudes towards the past that would reflect nostalgia proneness, and thus a priori selected and administered a subset of 8 items $(\alpha=.71)$ that had good face validity in terms of capturing the sentiment of nostalgia proneness (Appendix A). Items were rated on a 5-point scale $(1=$ not at all characteristic of me, $5=$ very characteristic of me). Zimbardo and Boyd (1999) and Bryant, Smart, and King (2005) found that positive perceptions of the past predicted self-reported indices of psychological adjustment, such as increased well-being and decreased anxiety or depression.

Participants were then randomly assigned to the MS or dental pain manipulation (Rosenblatt et al., 1989). They responded to two open-ended questions: "Briefly describe the emotions that the thought of your own death arouses in you" and "Jot down, as specifically as you can, what you think will happen to you physically as you die and once you are physically dead." The control condition consisted of parallel questions regarding the experience of dental pain, to control for general elicitation of negative thoughts. 
Previous research indicates that the initial reaction to an explicit death reminder is to remove such thoughts from focal attention; after a distraction, death thought accessibility is heightened and meaning-relevant defenses are initiated (Arndt, Cook, \& Routledge, 2004). Therefore, participants completed a puzzle distraction task after the salience manipulation. The puzzle task involved spending 3 minutes searching for television related words (e.g., channel, program) embedded in two letter matrices (Greenberg et al., 2000).

Next, participants completed the No Meaning Scale (Kunzendorf \& Maguire, 1995), which served as the dependent measure. This scale assesses how meaningful life is perceived to be (e.g., "Life has no meaning or purpose," "All strivings in life are futile and absurd"; $1=$ strongly disagree, 4 = strongly agree), with low scores indicating high levels of meaning in life $(\alpha=.88)$. The measure has previously been used to investigate the effects of MS and worldview defense on perceptions of meaning among the mildly depressed (Simon, Arndt, Greenberg, Pyszczynski, \& Solomon, 1998). In this research, Simon et al. established discriminant and convergent validity for the measure, showing that it correlates moderately with the Beck Depression Inventory (Beck, 1967) and the World Assumptions Scale (Janoff-Bulman, 1989). Given that 6 of the original 18 items explicitly refer to death, we administered the 12 non-death related items.

\section{Results}

We conducted a regression analysis, entering the main effects for the salience manipulation (dummy coded) and past perceptions variable (centered) in the first step and the interaction term in the second step (Aiken \& West, 1991). There were no main effects in the first step $(p s>.21)$. However, the two-way interaction in the second step was significant, $b=-.41$, $S E=.20, t=-2.05, p=.045$ (Figure 1). Given that we were interested in the relation between 
perceptions of the past and meaning after the threat of a mortality reminder, we proceeded with simple slope tests. As predicted, within the MS condition, the more positively participants viewed their past, the less they perceived life to be meaningless, $b=-.32, S E=.14, t=-2.34, p=$ .02. No relation was found within the control condition, $b=.09, S E=.15, t=-.63, p=.53$.

\section{Discussion}

These findings suggest that nostalgia is a meaning-providing resource. When the need for meaning was heightened because death thoughts were activated, the more positively individuals viewed their past, the more they perceived life as meaningful. ${ }^{2}$ Although these findings offer encouraging support for the notion that nostalgia can serve to buffer the attitudinal consequences of MS, they do not directly inform the capacity for nostalgia to protect individuals from cognitions about death per se. Such a prediction also follows from previous TMT research demonstrating that the psychological defenses which successfully protect people from the effects of MS reduce the accessibility of death-related thoughts (Arndt et al., 1997). Thus, if nostalgia is in fact buffering the effects of death salience, it should serve to decrease the accessibility of death thoughts. We test this possibility in the next experiment.

\section{Experiment 2}

Several studies have examined the role of death-thought accessibility in terror management processes (Arndt et al., 2004). Of present relevance, situationally bolstered or dispositionally strong meaning-providing structures can mitigate the elicitation of death-thought accessibility. Arndt and colleagues (1997) found that, after MS, providing American participants with an opportunity to demonstrate pro-American bias decreased the accessibility of death thoughts. Schmeichel and Martens (2005), Mikulincer and Florian (2002), and Harmon-Jones et al. (1997) found similar buffering effects for self-affirmation, self-serving bias, and self-esteem 
boosts, respectively. These distinct findings are telling because, in Arndt et al. and Mikulincer and Florian, the worldview bolstering opportunity came after mortality was made salient, whereas, in both Schmeichel and Martens and Harmon-Jones et al., the bolstering procedure came before mortality was made salient. Thus, either reinforcing a sense of meaning before or defending it after the threat of death is made salient will similarly buffer the effects of MS on death thought accessibility.

We built upon the findings of Experiment 1 to explore further the potential for nostalgia to buffer MS effects. First, Experiment 1 used an arguably broad and potentially ambiguous nostalgia measure. Though Zimbardo and Boyd (1999) indicated that perceptions of the past may be related to nostalgia, their measure examines broadly the extent to which one perceives the past as positive or negative, and it does not directly assess how these perceptions reflect actual nostalgia proneness. Therefore, we moved in Experiment 2 toward a more face valid and focused measure of nostalgia proneness. Second, to assess more directly nostalgia's potential to protect from death concerns, we examined the association between nostalgia proneness and the accessibility of death thoughts after MS. Third, we considered potential confounds between nostalgia proneness and other individual differences that may serve a MS buffering function by controlling for individual differences in self-esteem and satisfaction with life. If nostalgia proneness buffers concerns about mortality, after being reminded of death, the more nostalgic one tends to be, the less death thoughts should be accessible. Further, this effect should emerge independently of individual differences in self-esteem and satisfaction with life.

\section{Method}

Forty participants (31 female, 7 male, 2 unidentified) were presented with a packet containing the materials. After filler personality measures, participants completed the 
Southampton Nostalgia Scale (SNS) consisting of 5 items (one reversed scored). The measure showed good reliability ( $\alpha=.92$; Appendix B). Higher scores reflect greater nostalgia proneness. A separate pilot study $(\mathrm{N}=38)$ found a significant correlation between the SNS and the 8 TPI items used in Experiment $1, r=.36 p<.05$. In the same study, the SNS correlated $(r=.40 p<$ .01) with the established Batcho Nostalgia Scale (1995).

Next, participants were randomly assigned to complete either the MS or dental pain writing task and the puzzle delay task, as in Experiment 1. Finally, participants were presented with a "Word Completion Task" that was ostensibly being tested for future studies but was actually a death thought accessibility measure (Arndt et al., 1997; Mikulincer \& Florian, 2000). The measure presented participants with 28 word fragments, 6 of which could be completed with a neutral or death-related word. For example, the fragment $\mathrm{COFF}_{--}$could be completed as COFFEE (a neutral word) or COFFIN (a death-related word). The possible death-related words were buried, murder, grave, skull, stiff, and coffin. Death-thought accessibility scores were computed by summing the number of death words created by each participant. Higher scores thus indicate greater accessibility of death-related thoughts.

In addition, prior to the experiment, participants took part in a pretest screening in which they completed a measure of self-esteem (Rosenberg, 1965; $\alpha=.87$ ) and psychological wellbeing (Satisfaction With Life or SWL; Diener, Emmons, Larsen, \& Griffen, 1985; $\alpha .73$ ).

\section{Results}

We conducted a regression analysis to test the hypothesis that nostalgia proneness buffers the effects of MS on death-thought accessibility. In the first step, a significant nostalgia proneness main effect emerged, $b=-.34, S E=.14, t=-2.21, p=.03$. This effect was qualified by a significant interaction in the second step, $b=.64, S E=.27, t=-2.37, p=.02$ (Figure 2). 
Within the MS condition, as predicted, increased nostalgia proneness was associated with decreased death-thought accessibility, $b=-.69, S E=.21, t=-3.31, p=.002$. However, within the control condition, there was no such relation, $b=-.06, S E=.17, t=-.33, p=.74$.

Next, we considered whether the effect of nostalgia proneness was independent of trait differences in self-esteem and satisfaction with life. Though self-esteem and SWL were significantly correlated with one another $(r=.41, p=.02)$, the correlations between self-esteem and nostalgia proneness $(r=-.05, p=.80)$ and SWL and nostalgia proneness $(r=-.18, p=.33)$ did not approach significance. In addition, we ran the previous regression models adding selfesteem and SWL and their respective interactions with MS. No main or interactive effects involving self-esteem (all $p s>.25$ ) or SWL (all $p s>.55$ ) emerged. Furthermore, the previously reported significant interaction and simple slope tests remained significant (all $p s<.05$ ). Thus, there is no evidence that the effect of nostalgia proneness can be attributed to differences in selfesteem or SWL.

\section{Discussion}

When death thoughts were activated, greater nostalgia proneness was associated with decreased death-thought accessibility. This effect remained significant after controlling for selfesteem and SWL. Using a different and more face valid measure of nostalgia proneness as well as a more direct test of MS buffering (i.e., a death accessibility measure), these findings converge with those of Experiment 1 to establish that nostalgia protects from death threat.

However, given that Experiments 1 and 2 used a trait measure of nostalgia, an experimental manipulation of nostalgia would be needed to draw confident inferences. This is the objective of the next experiment. 


\section{Experiment 3}

The current experiment builds upon the findings of Experiment 2 to investigate the potential for nostalgia to buffer death-thought accessibility following MS. To manipulate nostalgia, we implemented a procedure introduced by Wildschut et al. (2006), whereby participants are given prompts to wax nostalgic or not. In Wildschut et al., this manipulation effectively induced nostalgia and resulted in theoretically predicted effects. Here, we hypothesized that MS would, in the absence of nostalgic reverie, lead to a delayed increase in death-thought accessibility. However, if nostalgia provides a protective buffer against deathrelated ideation, then, following MS, nostalgia should lead to equivalent levels of death-thought accessibility as those unexposed to reminders of death. The hypothesized pattern is thus for death-thought accessibility to be equally low in all conditions except when nostalgia is not induced and mortality is made salient. This hypothesized " 1 vs. 3 " pattern follows from the findings of the first two experiments (Figures 1 and 2).

\section{Method}

Seventy-five participants (48 female, 26 male, 1 unidentified) were first given a packet of materials containing filler personality measures and then either the nostalgia or an ordinary-event writing task (Wildschut et al., 2006). In the nostalgic condition, participants read:

Bring to mind a nostalgic event in your life. Specifically, try to think of a past event that makes you feel most nostalgic. Write down four keywords relevant to this event (i.e., words that sum up the gist of the experience). Now take a few moments to think about the nostalgic event and how it makes you feel, then turn to the next page. 
In the control condition, participants read:

Bring to mind an ordinary event in your daily life — an event that took place in the last week. Write down four keywords relevant to this event (i.e., words that sum up the gist of the experience). Now take a few moments to think about the ordinary event and how it makes you feel, then turn to the next page.

Next, participants received either the MS (as in Experiments 1-2) or control manipulation. Control participants wrote about failing an important exam (Pyszczynski et al., 2004) to assess whether MS effects are different from any self-relevant threat. Following a short reading distraction task, participants completed the death-thought accessibility measure of Experiment 2.

\section{Results}

The hypothesized pattern was that death-thought accessibility will only be elevated in one of the four conditions (i.e., the MS/non-nostalgia condition). If nostalgia is a successful buffer of MS, levels of death-thought accessibility in the MS/nostalgia condition should be similar to levels of death-thought accessibility in the remaining two non-MS conditions. We carried out a series of orthogonal contrasts (Rosenthal \& Rosnow, 1985) that allowed for a precise examination of the hypothesized pattern (Figure 3$)^{3}$.

First, to determine if MS, in the absence of nostalgia, successfully increased deaththought accessibility, this condition was contrasted with the other three conditions (MS/nostalgia condition, non-MS/nostalgia condition, and non-MSe/non-nostalgia condition). This contrast was significant, such that participants in the MS/non-nostalgic condition $(M=2.11, S D=.81)$ showed greater death-thought accessibility than participants in all other conditions pooled $(M=$ $1.48, S D=.89), F(1,73)=7.21, p<.01$. Second, to test the buffering effect of nostalgia, the 
MS/nostalgia condition was contrasted with the remaining two non-MS conditions. As predicted, the MS/nostalgia condition $(M=1.56, S D=.78)$ did not differ significantly from the two nonMS conditions $(M=1.45, S D=.95), F(1,54)=.18, p>.65$. Finally, the two remaining non-MS conditions were contrasted. The non-MS/nostalgia condition $(M=1.43, S D=.93)$ did not differ from the non-MS/ non-nostalgia condition $(M=1.47, S D=1), F(1,36)=.02, p>.85$.

We also conducted supplemental simple mean comparisons to further examine these patterns. Within non-nostalgia conditions, MS participants $(M=2.11, S D=.81)$ showed higher death-thought accessibility than control participants $(M=1.47, S D=1.00), F(1,34)=4.39, p<$ .05 . However, within nostalgia conditions, $\mathrm{MS}(M=1.56, S D=.78)$ and control $(M=1.43, S D=$ .93 ) participants did not differ, $F(1,37)=.21, p>.60$. In addition, within MS conditions, nostalgia participants $(M=1.56, S D=.78)$ showed lower death-thought accessibility than nonnostalgia participants $(M=2.11, S D=.90), F(1,35)=4.40, p<.05$. However, within non-MS control conditions, nostalgia $(M=1.43, S D=.93)$ and non-nostalgia control $(M=1.47, S D=$ 1.00) participants did not differ, $F(1,36)=.02, p>.85$. These findings converge with those from the orthogonal contrasts.

As in Experiment 2, we sought to determine whether the effect of nostalgia could be attributed to other variables. Previous research indicates that nostalgia can increase positive affect, self-esteem, and feelings of relatedness; as such, we wanted to take into consideration these three constructs. In the nostalgia and control conditions, participants wrote four keywords related to the experience upon which they reflected. Using the Linguistic Inquiry and Word Count program (LIWC; Pennebaker \& Francis, 1999), we examined the content of these keywords. The LIWC (a) classifies words as to whether they tap particular constructs (e.g., positive affect) using an established dictionary of over 2300 words and word stems and then (b) 
generates variables representing the proportion of words in the text that relate to the constructs of interest. The LIWC contains categories for affect (both positive and negative) and social themes, but does not have a category for self-esteem. However, as a loose proxy for self-esteem, we used the LIWC category for achievement which captured all of the keywords that appeared to relate to self-esteem (e.g., winning, worthy, intelligent). There was no difference between nostalgia and control conditions on achievement $(p=.30)$. However, nostalgia participants, compared to control participants, wrote more positive affect relative to negative affect related words $(p=$ $.045)$ and more social-related words $(p=.03)$. However, controlling for either variable and their respective interactions with MS did not impact the previously reported contrasts. The previously reported significant contrast remained significant $(p s=$ or $<.05)$ and the remaining previously reported non-significant contrasts remained non-significant (all $p \mathrm{~s}>.66$ ).

\section{Discussion}

Experiment 3 built upon Experiment 2's findings to demonstrate that nostalgia buffers the effects of MS on the accessibility of death-related thoughts. In the absence of a nostalgia manipulation, as in previous research, MS significantly increased the accessibility of deathrelated thoughts. However, when nostalgia was induced, MS did not increase death-thought accessibility relative to control conditions. These findings are particularly insightful, because in the previous two experiments nostalgia was measured, not manipulated. Given that nostalgia was experimentally induced, these findings more confidently indicate that nostalgia does provide a successful buffer against death-related cognition. Furthermore, the effect of nostalgia was not mediated by achievement, affect, or social relationships.

General Discussion 
This research converges in suggesting the utility of nostalgia as a self-protection mechanism against death-related concerns. In Experiment 1, when reminded of mortality, the more positively individuals thought about the past, the more they perceived life as meaningful. In Experiment 2, this protective function was further highlighted: The more nostalgic individuals were, the less death thoughts were accessible after MS. This was a critical extension of Experiment 1's findings, because it (a) conceptually replicated the terror management function of nostalgia with a different measure of nostalgia proneness, (b) demonstrated the predicted effect at the cognitive level, thus providing a more precise test of the buffering effect, and (c) suggested the effect of nostalgia proneness is not attributable to trait differences in self-esteem or well-being. Finally, Experiment 3 buttressed previous findings by demonstrating a buffering effect on death-thought accessibility with manipulated, as opposed to measured, nostalgia. In addition, this experiment built upon the findings of Experiment 2 to suggest that nostalgia is a unique existential resource as the effect of nostalgia was not mediated by feelings of achievement (a proxy for self-esteem), affect, or the salience of social bonds. As can be seen graphically by comparing the three figures, similar patterns of data emerged using three distinct operations of nostalgia and two dependent measures operating at different levels of analysis (i.e., perceptions of meaning at an attitudinal level and death accessibility at a cognitive level).

The current findings are of conceptual significance to TMT, because they elucidate a previously unexplored manner in which individuals protect themselves from death concerns: by using their temporal thinking abilities to conjure up past experiences that can meet defensive needs in the present. Previous research demonstrated how the use of current structures (e.g., romantic relationships; Florian, Mikulincer, \& Hirschberger, 2002) protects individuals from mortality concerns. The present research, on the other hand, focuses on one's ability to reflect 
upon past events for such protection. Interestingly, temporal consciousness, by allowing individuals to think about the future, is one of the capacities that facilitate mortality awareness (Becker, 1971). Fortunately, as the current findings suggest, temporal consciousness may also provide solutions to the problem it helped create by allowing individuals to draw upon past experiences that increase meaning and reduce death-thought accessibility (Routledge \& Arndt, 2005; Sedikides, Wildschut, Gaertner, Routledge, \& Arndt, in press). This is not to say that some temporal reflections will not be threatening. In McGregor, Zanna, Holmes, and Spencer (2001), for example, inducing a sense of temporal discontinuity engendered defensiveness. Critically, however, McGregor and colleagues' manipulation of temporal discontinuity differs from the present consideration of nostalgia in several ways (e.g., it asks participants to think about how events from their past might change $30+$ years into the future). With this in mind, issues regarding how and when the past can provide solace or induce existential concerns remain important for future research.

An additional challenge for future research is to explore how nostalgia is similar to and distinct from other terror management defenses. Nostalgia bolsters self-esteem and social bonds (Wildschut et al., 2006) and self-esteem and social bonds buffer the effects of MS (Mikulincer et al., 2003; Pyszczynski et al., 2004). Yet the current research provides preliminary evidence that nostalgia is not reducible to these other constructs. Further, though nostalgia increases positive affect and research suggests that positive mood provides feelings of meaningfulness in life (King et al., 2006), the current research shows that the effects of nostalgia are not mediated by affect. The present research thus offers the generative invitation to further inquiry. One possibility is that nostalgia is often related to momentous and thus highly meaningful life events (Wildschut et al., 2006) and recent research highlights how MS triggers efforts to perceive the world in 
coherent and meaningful ways (Landau et al., 2004). Thus, nostalgia may serve a terror management function by directly bolstering feelings of meaning, as opposed to indirectly providing such feelings via self-esteem and social bonds. Indeed, in Experiment 1, when the need for meaning was heightened by a MS induction, there was a strong relation between perceptions of the past and meaning. An additional possibility that merits future consideration is the extent to which nostalgia may foster a sense of self-continuity, allowing individuals to perceive themselves as meaningful entities over time.

The current findings may also be informative when considering the often socially and personally disadvantageous nature of terror management responses. When facing mortality concerns, individuals frequently respond in a disparaging manner toward others who belong to different (e.g., social) groups (Lieberman, Arndt, Personius, \& Cook, 2001) and engage in risky behavior (e.g., sun-tanning, Routledge, Arndt, \& Goldenberg, 2004) to the extent that such behavior bolsters self-esteem. Our findings suggest a more socially and personally advantageous terror management strategy. If individuals can meet defense needs by reflecting on the past, they may be less inclined to act on opportunities in the present to derogate outgroups or take unnecessary health risks in the service of self-esteem maintenance.

These ideas could be applied to the broader literature on social conflict and selfaffirmation. Conditions that threaten one's self-worth (Fein \& Spencer, 1997) and important identifications (Burris \& Rempel, 2004) increase in-group bias. Further, opportunities for selfaffirmation reduce deleterious responses to health and identity threat (Creswell et al., 2005; Schmeichel \& Martens, 2005). Future research could investigate the potential for nostalgia to induce similar palliative effects after individuals are exposed to conditions of threat. Given the 
present effects of nostalgia, such potential is promising and pragmatically relevant to how individuals navigate their daily affairs.

Finally, the present research provides a useful foundation upon which to base the effectiveness of reminiscence therapy in treating depression (Arean et al., 1993; Bohlmeijer, Valenkamp, Westerhof, Smit, \& Cuijpers, 2003). One contributing factor to depression is the inability to sustain a meaningful view of the world (Simon et al., 1998). To the extent that nostalgia provides a mechanism for investing in one's worldview, reflecting on the past may help bolster conceptions of meaning and thus reinforce the aims of the therapeutic intervention. 
A blast from the past 20

\section{References}

Arean, P. A., Perri, M. G., Nezu, A. M., Schein, R. L., Christopher, F., Joseph, T. X. (1993).

Comparative effectiveness of social problem solving therapy and reminiscence therapy as treatment for depression in older adults. Journal of Consulting and Clinical Psychology. 61, 1003-1010.

Aiken, L. S. \& West, S. G. (1991). Multiple regression: testing and interpreting interactions. Newbury Park, CA: Sage Publications.

Arndt, J., Cook, A., \& Routledge, C. (2004). The blueprint of terror management: Understanding the cognitive architecture of psychological defense against the awareness of death. In J. Greenberg, S. L., Koole, \& T. Pyszczynski (Eds.), Handbook of experimental existential psychology (pp. 35-53). New York: Guilford Press.

Arndt, J., Greenberg, J., Solomon, S., Pyszczynski, T., \& Simon, L. (1997). Suppression, accessibility of death-related thoughts, and cultural worldview defense: Exploring the psychodynamics of terror management. Journal of Personality and Social Psychology, $73,5-18$.

Batcho, K. I. (1995). Nostalgia: A psychological perspective. Perceptual and Motor Skills, 80, $131-143$

Beck, A. T. (1967). Depression: Clinical, experimental, and theoretical aspects. New York: Harper and Row.

Becker, E. (1971). The birth and death of meaning (2nd ed.) New York: Free Press.

Bohlmeijer, E., Valenkamp, M., Westerhof, G., Smit, F., Cuijpers, P. (2005). Creative reminiscence as an early intervention for depression: results of a pilot project. Aging and Mental Health, 9, 302-304. 
A blast from the past 21

Bryant, F., Smart, C. M., \& King, S. P. (2005). Using the past to enhance the present: Boosting happiness through positive reminiscence. Journal of Happiness Studies, 6, 227-260.

Burris, C. T., \& Rempel, J. K. (2004). "It's the end of the world as we know it": Threat and the spatial-symbolic self. Journal of Personality and Social Psychology, 86, 19-42.

Creswell, J. D., Welch, W. T., Taylor, S. E., Sherman, D. K., Gruenewald, T. L., \& Mann, T. (2005). Affirmation of personal values buffers neuroendocrine and psychological stress responses. Psychological Science, 16, 846-851.

Diener, E., Emmons, R., Larsen, J., Griffin, S. (1985). The Satisfaction With Life Scale. Journal of Personality Assessment, 49, 71-75.

Fein, S., \& Spencer, S. J. (1997). Prejudice as self-image maintenance: Affirming the self through derogating others. Journal of Personality and Social Psychology, 73, 31-44.

Florian, V., Mikulincer, M., \& Hirschberger, G. (2002).The anxiety-buffering function of close relationships: Evidence that relationship commitment acts as a terror management mechanism. Journal of Personality and Social Psychology, 82, 527-542.

Greenberg, J., Arndt, J., Simon, L., Pyszczynski, T., \& Solomon, S. (2000). Proximal and distal defenses in response to reminders of one's mortality: Evidence of a temporal sequence. Personality and Social Psychology Bulletin, 26, 91-99.

Greenberg, J., Pyszczynski, T., \& Solomon, S. (1986). The causes and consequences of a need for self-esteem: a terror management theory. In R. F. Baumeister (Ed.), Public self and private self (pp.189-212). New York: Springer-Verlag.

Greenberg, J., Solomon, S., \& Arndt, J. (in press). A uniquely human motivation: Terror management. In J. Shah \& W. Gardner (Eds.), Handbook of motivation science. New York: Guilford. 
Harmon-Jones, E., Simon, L., Greenberg, J., Pyszczynski, T., Solomon, S., \& McGregor, H. (1997). Terror management theory and self-esteem: Evidence that increased self-esteem reduces mortality salience effects. Journal of Personality and Social Psychology, 72, 2436.

Janoff-Bulman, R. (1989). Assumptive worlds and the stress of traumatic events: Applications of the schema construct. Social Cognition, 7, 113-136.

Kunzendorf, R. G., \& Maguire, D. (1995). Depression: The reality of "no meaning” versus the delusion of negative meaning. Unpublished manuscript. Lowell, MA: University of Massachusetts.

King, L. A., Hicks, J. A, Krull, J., Del Gaiso, A. K. (2006). Positive affect and the experience of meaning in life. Journal of Personality and Social Psychology, 90, 179-196.

Landau, M. J., Johns, M., Greenberg, J., Pyszczynski, T., Solomon, S., \& Martens, A. (2004). A function of form: Terror management and structuring of the social world. Journal of Personality and Social Psychology, 87, $190-210$.

Lieberman, J. D., Arndt, J., Personius, J., \& Cook, A. (2001). Vicarious annihilation: The effect of mortality salience on perceptions of hate crimes. Law and Human Behavior, 25, 547566.

McGregor, I., Zanna, M. P., Holmes, J. G., \& Spencer, S. J. (2001). Compensatory conviction in the face of personal uncertainty: Going to extremes and being oneself. Journal of Personality and Social Psychology, 80, 472-488.

Mikulincer, M., \& Florian, V. (2002). The effect of mortality salience on self-serving attributions - evidence for the function of self-esteem as a terror management mechanism. Basic and Applied Social Psychology, 24, 261-271. 
Mikulincer, M., Florian, V., \& Hirschberger, G. (2003). The existential function of close relationships: Introducing death into the science of love. Personality and Social Psychology Review, 7, 20-40.

Pennebaker, J. W., \& Francis, M. E. (1999). Linguistic Inquiry and Word Count: LIWC. Mahwah, NJ: Erlbaum.

Pyszczynski, T., Greenberg, J., Solomon, S., Arndt, J., \& Schimel, J. (2004). Why do people need self-esteem?: A theoretical and empirical review. Psychological Bulletin, 130, 435468.

Rosenberg, M. (1965). Society and the adolescent self-image. Princeton, NJ: Princeton University Press.

Rosenblatt, A., Greenberg, J., Solomon, S., Pyszczynski, T., \& Lyon, D. (1989). Evidence for terror management theory I: The effects of mortality salience on reactions to those who violate or uphold cultural values. Journal of Personality and Social Psychology, 57, 681690.

Rosenthal, R., \& Rosnow, R. L. (1985). Contrast analysis. New York, NY: Cambridge.

Routledge, C., \& Arndt, J. (2005). Time and terror: Managing temporal consciousness and the awareness of mortality. In A. Strathman \& J. Joireman (Eds.), Understanding behavior in the context of time: Theory, research, and applications. (pp. 59-84).Mahwah, NJ: Erlbaum.

Routledge, C., Arndt, J., \& Goldenberg, J. L. (2004). A time to tan: Proximal and distal effects of mortality salience on intentions to sun-tan. Personality and Social Psychology Bulletin, $30,1347-1358$. 
Schmeichel, B. J., \& Martens, A. (2005). Self-affirmation and mortality salience: Affirming values reduces worldview defense and death-thought accessibility. Personality and Social Psychology Bulletin, 31, 658-667.

Sedikides, C., Wildschut, T., Arndt, J., \& Routledge, C. D. (2006). Affect and the self. In J. P. Forgas (Ed.), Affect in social thinking and behavior: Frontiers in social psychology (pp. 197-215). New York, NY: Psychology Press.

Sedikides, C., Wildschut, T., Gaertner, L., Routledge, C., \& Arndt, J. (in press). Nostalgia as enabler of self-continuity. In F. Sani (Ed.), Individual and collective self-continuity: Psychological perspectives. Mahwah, NJ: Lawrence Erlbaum Associates.

Sedikides, C., Wildschut, T., \& Baden, D. (2004). Nostalgia: Conceptual issues and existential functions. In J. Greenberg, S. Koole, \& T. Pyszczynski (Eds.), Handbook of experimental existential psychology (pp. 200-214). New York: Guilford.

Simon, L., Arndt, J., Greenberg, J., Solomon, S., \& Pyszczynski, T. (1998). Terror Management and meaning: Evidence that the opportunity to defend the worldview in response to mortality salience increases the meaningfulness of life in the mildly depressed. Journal of Personality, 66, 359-382.

Wildschut, T., Sedikides, C., Arndt, J., \& Routledge, C. (2006). Nostalgia: Content, triggers, functions. Journal of Personality and Social Psychology, 91, 975-993.

Zimbardo, P. G., \& Boyd, J. N. (1999). Putting time in perspective: A valid, reliable individualdifference metric. Journal of Personality and Social Psychology, 77, 1271-1288. 


\section{Footnotes}

1. Note that, in all experiments, participants (a) were Introductory Psychology students at a large Midwestern university, (b) completed all materials in groups of 1-4 as part of a purported study on the interrelations among personality characteristics, (c) were given identical instructions across conditions, and (d) were thoroughly debriefed. No gender effects were found in any experiment.

2. Simon, Arndt, Greenberg, Pyszcsynski, and Solomon (1998) found that, while mildly depressed individuals responded to MS and the opportunity to defend their worldview with increased perceptions of meaning, MS did not affect scores on this measure in the absence of the opportunity to defend the worldview. On the one hand, this finding suggests that both nostalgia and worldview defense reflect increased engagement in resources that provide existential protection. On the other, it is unclear why, given the present results, MS did not exert a more straightforward effect on meaning. One potentially important procedural difference is that, in Simon et al., the No-meaning scale was administered after participants had been exposed to distraction exercises and worldview threatening and supportive essays, whereas, in the present experiment, the scale was administered immediately following a distraction exercise. Thus, in Simon et al., exposure to the worldview relevant targets may have influenced the direct effect of MS on perceptions of meaning. Future research is needed to address this issue conclusively.

3. A conventional two-way ANOVA revealed a marginal main effect indicating higher death thought accessibility for MS $(M=1.84, S D=.83)$ compared to control participants $(M=$ $1.45, S D=.95), F(1,71)=3.45, p=.07$, but no significant interaction, $F(1,71)=1.53, p=.22$. 
Appendix A: (8 items from the TPI used to measure nostalgia proneness in Experiment 1)

It gives me pleasure to think about my past.

I often think of what I should have done differently in my life. (reversed)

On balance, there is much more good to recall than bad in my past.

I think about the good things that I have missed out on in my life. (reversed)

Happy memories of good times spring readily to mind.

The past has too many unpleasant memories that I prefer not to think about. (reversed)

I get nostalgic about my childhood.

I think about the bad things that have happened to me in the past. (reversed) 
Appendix B: (Southampton Nostalgia Scale used in Experiment 2)

1. How often do you experience nostalgia?

$\begin{array}{ccccccc}1 & 2 & 3 & 4 & 5 & 6 & 7 \\ \text { Very rarely } & & & & & & \text { very frequently }\end{array}$

2. How prone are you to feeling nostalgic?

$\begin{array}{ccccccc}1 & 2 & 3 & 4 & 5 & 6 & \begin{array}{c}7 \\ \text { very much }\end{array}\end{array}$

3. Generally speaking, how often do you bring to mind nostalgic experiences?

$\begin{array}{ccccccc}1 & 2 & 3 & 4 & 5 & 6 & 7 \\ \text { Very rarely } & & & & & & \text { very frequently }\end{array}$

4. Specifically, how often do you bring to mind nostalgic experiences?

At least once a day

Three to four times a week

Approximately twice a week

Approximately once a week

Once or twice a month

Once every couple of months

Once or twice a year

5. How important is it for you to bring to mind nostalgic experiences?

$\begin{array}{ccccccc}1 & 2 & 3 & 4 & 5 & 6 & \begin{array}{c}7 \\ \text { very much }\end{array} \\ \text { Not at all } & & & & & & \end{array}$


A blast from the past 28

Figure 1

The effects of nostalgia proneness and mortality salience on perceptions of meaning in Experiment 1

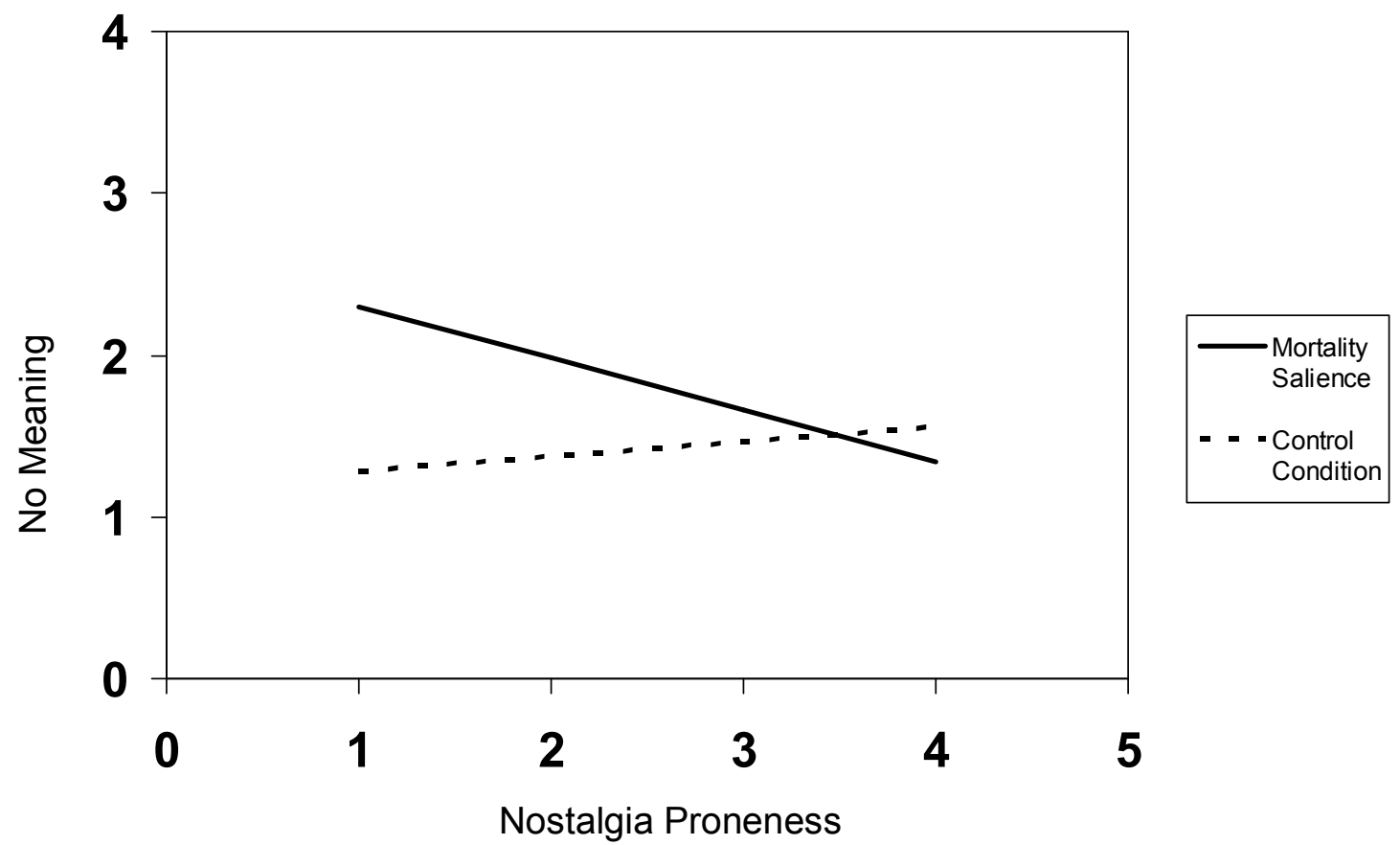

Note: Higher scores on the No Meaning Scale reflect lower levels of perceptions of meaning in life. 
Figure 2

The effects of nostalgia proneness and mortality salience on death-thought accessibility in Experiment 2

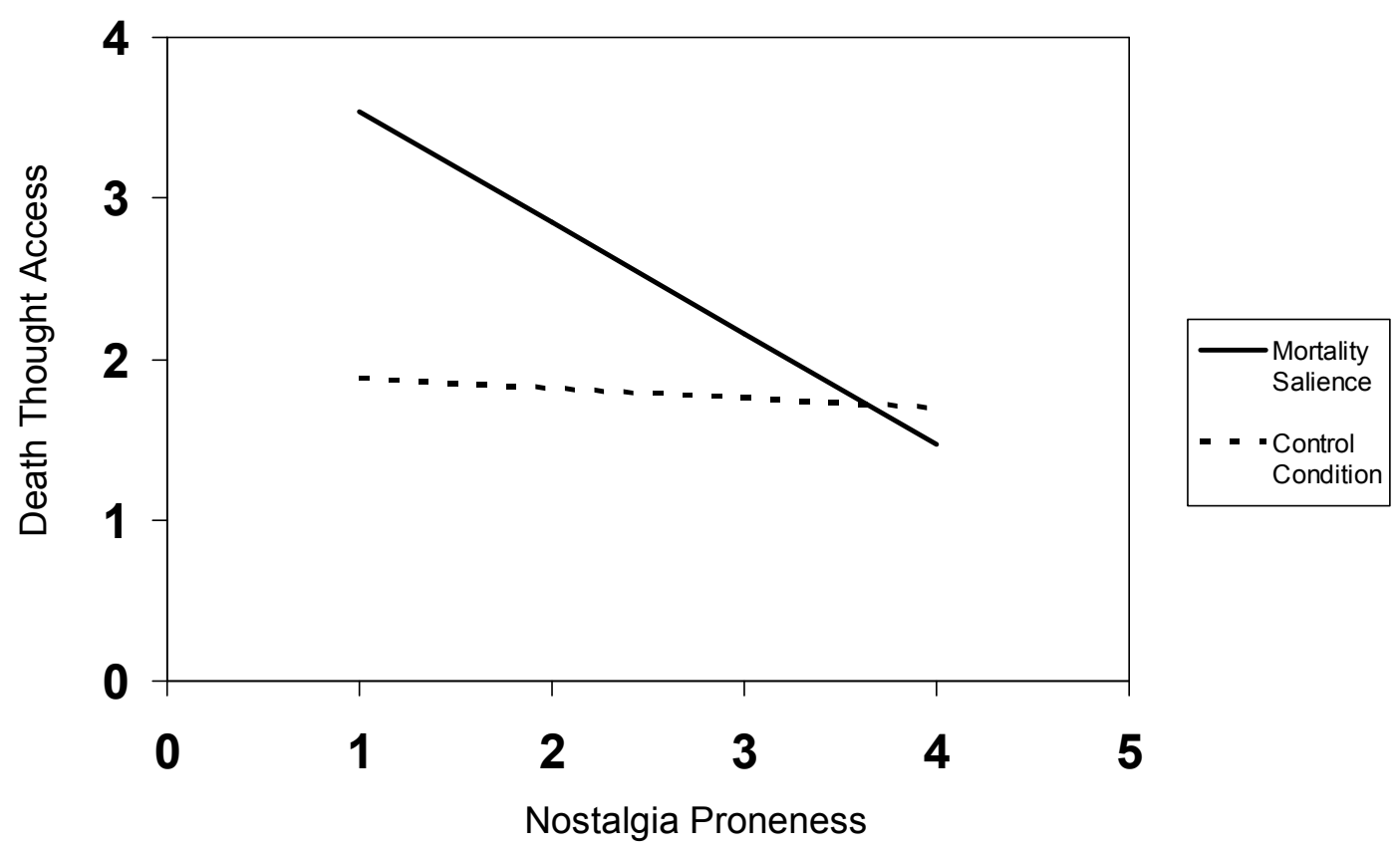

Note: Higher scores on death-thought access reflect increased accessibility of death-related thoughts. 
A blast from the past 30

Figure 3

The effects of nostalgia and mortality salience on death-thought accessibility in Experiment 3

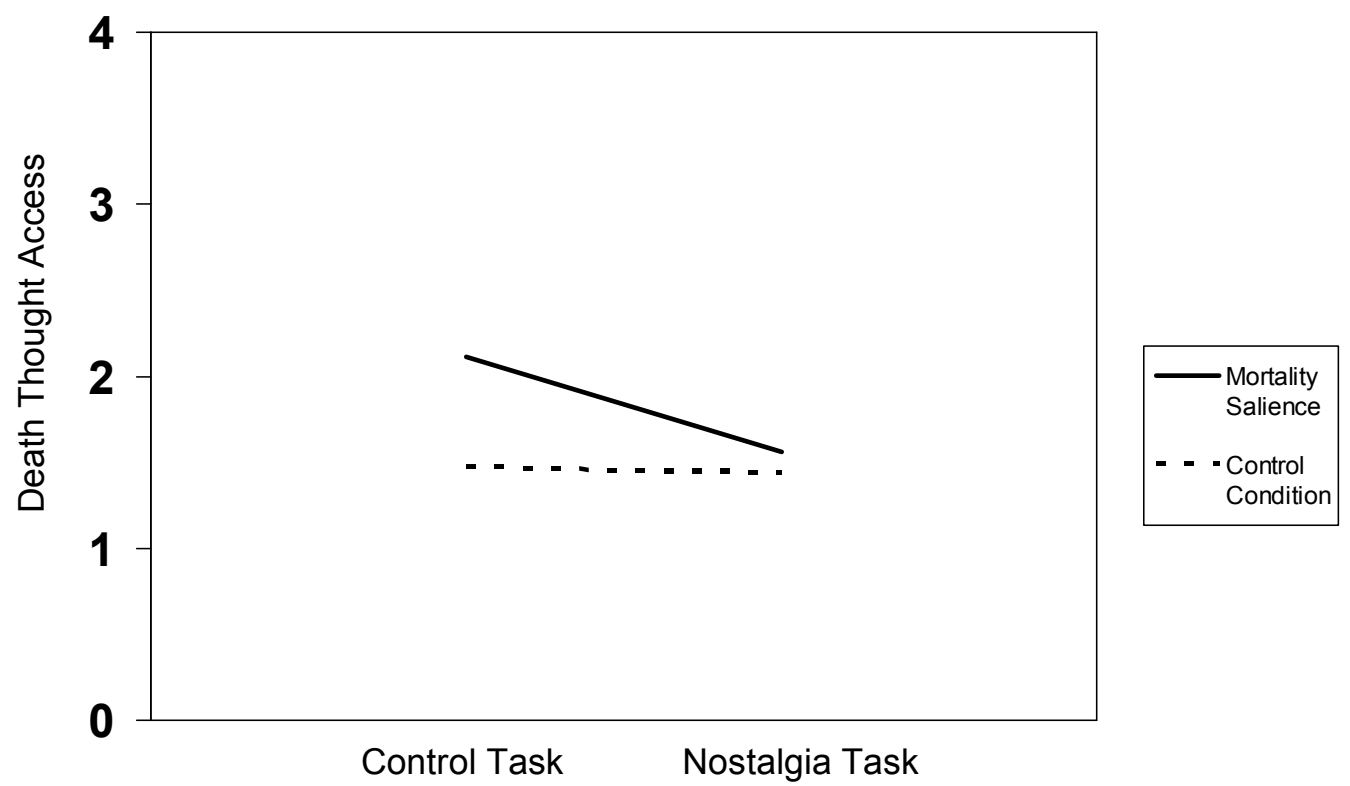

Note: Higher scores on death-thought access reflect increased accessibility of death-related thoughts. 